\title{
PENGEMBANGAN MEDIA PEMBELAJARAN ELEKTRONIKA ANALOG DAN DIGITAL BERBASIS CORELDRAW DAN ADOBE FLASH
}

\author{
Muhammad Yusuf Mappeasse ${ }^{1}$, Hasrul $^{2}$, Dyah Vitalocca ${ }^{3}$ \\ ${ }^{1}$ Pendidikan Teknik Elektro, Universitas Negeri Makassar \\ mappeasseyusuf@gmail.com \\ ${ }^{2}$ Pendidikan Teknik Elektro, Universitas Negeri Makassar \\ Hasrulbakri@unm.ac.id \\ ${ }^{3}$ Pendidikan Teknik Informatika dan Komputer, Universitas Negeri Makassar \\ dyah_vitalocca@unm.ac.id
}

\begin{abstract}
ABSTRAK
Penelitian ini bertujuan untuk membuat media pembelajaran berbasis multimedia pada mata kuliah Elektronika Analog dan Digital. Metode Penelitian yang digunakan adalah metode R\&D (Research and Development). R\&D (Research and Development) adalah suatu proses atau langkah-langkah untuk mengembangkan suatu produk baru, atau menyempurnakan produk yang telah ada, yang dapat dipertanggung jawabkan. Untuk mengetahui cara membuat media pembelajaran berbasis multimedia dan mengetahui tanggapan mahasiswa terhadap media pembelajaran, penelitian ini dilaksanakan melalui prosedur validasi ahli sebagai validor, uji coba kelompok kecil pada 7 mahasiswa, dan uji coba kelompok besar pada 34 mahasiswa. Teknik pengumpulan data pada penelitian ini mengunakan angket yang kemudian disebarkan kepada responden untuk mengetahi tanggapan mahasiswa Prodi Pendidikan Teknik Informatika dan Komputer terhadap Multimedia Pembelajaran Elektronika Analog dan Digital yang telah dibuat menggunakan aplikasi CorelDRAW X6 dan Adobe Flash Cs6. Teknik analisis data yang digunakan pada penelitian ini adalah teknik analisis deskriptif. Berdasarkan hasil analisis statistic deskriptif menunjukan bahwa tanggapan mahasiswa terhadap multimedia pembelajaran berbasis multimedia berada pada kategori sangat baik dengan presentase $91,2 \%$ dan berdasarkan hasil validasi oleh ahli media bahwa media ini layak digunakan sebagai media pembelajaran pada mata kuliah Elektronika Analog dan Digital.
\end{abstract}

Kata Kunci: CorelDrawX6, Adobe Flash Cs6, Media Pembelajaran, Elektronika Analog dan Digital

\section{DEVELOPMENT OF ANALOG AND DIGITAL ELECTRONICS LEARNING MEDIA BASED ON CORELDRAW AND ADOBE FLASH}

\begin{abstract}
This study aims to create multimedia-based learning media in Analog and Digital Electronics courses. The research method used is the $R \& D$ (Research and Development) method. $R \& D$ (Research and Development) is a process or steps to develop a new product, or improve an existing product, which can be accounted for. To find out how to make multimedia-based learning media and to find out student responses to learning media, this research was carried out through expert validation procedures as validators, small group trials on 7 students, and large group trials on 34 students. The data collection technique in this study used a questionnaire which was then distributed to respondents to find out the responses of students of the Informatics and Computer Engineering Education Study Program towards Analog and Digital Electronics Learning Multimedia which had been created using the CorelDRAW X6 and Adobe Flash Cs6 applications. The data analysis technique used in this research is descriptive analysis technique. Based on the results of descriptive statistical analysis, it shows that student responses to multimedia-based learning are in the very good category with a percentage of $91.2 \%$ and based on validation results by media experts that this media is suitable for use as learning media in Analog and Digital Electronics courses.
\end{abstract}

Keyword: CorelDrawX6, Adobe Flash Cs6, Learning Media, Analog and Digital Electronics 


\section{PENDAHULUAN}

Dalam proses pembelajaran peserta didik sebagai penerima materi berharap penyampaian materi yang tidak bersifat abstrak namun informasi pembelajaran yang jelas dan mudah dipahami sehingga terjadi komunikasi yang jelas dalam proses pembelajaran. hambatan-hambatan yang ditemui dalam proses belajar mengajar yang menyebabkan terjadinya ketidak lancaran komunikasi antara lain: verbalisme, perhatian yang bercabang, kekacauan penafsiran, tidak adanya tanggapan, kurang perhatian, keadaan fisik dan lingkungan yang mengganggu, dan sikap pasif anak didik [1].

Proses pembelajaran matakuliah Elektronika Analog dan Digital dapat dilakukan melalui berbagai media dan metode. Namun kenyataanya di kelas, proses pembelajaran tidak sesuai harapan. Pentingnya peran media pembelajaran seringkali tidak dimaksimalkan karena kreativitas dosen atau tenaga pendidik dan peserta didik untuk membuat media sederhana sangatlah kurang. Sementara itu Mata Kuliah Elektronika Analog dan Digital merupakan mata kuliah wajib pada semua program studi pada Jurusan Pendidikan Teknik Elektro Universitas Negeri Makassar yang memiliki tingkat kesulitan yang tinggi. Rata-rata hasil belajar.

Peningkatan hasil belajar perlu dilakukan melalui proses pembelajaran dengan menggunakan metode dan media pembelajaran yang tepat. Salah satu cara yang dapat dilakukan yaitu dengan melakukan inovasi dalam proses pembelajaran. Dengan inovasi tersebut, tentunya diharapakan proses pembelajaran di dalam kelas memiliki suasana baru yang sifatnya fositif dan dapat memberikan dampak terhadap hasil belajar peserta didik. Penulis berfikir bahwa media pembelajaran berbasis multimedia merupakan salah satu solusi dan inovasi perbaikan dalam proses pembelajaran. Sebagaimana dikemukakan oleh [2] bahwa dalam proses pembelajaran hendaknya menggunakan urutan belajar dari gambar atau film (iconic respresentation of expertment), kemudian belajar dengan simbol, yaitu menggunakan kata-kata (symbolic representation), hal tersebut berlaku tidak hanya untuk anak-anak namun dapat juga untuk orang dewasa.

Berdasarkan pernyataan di atas tentu dapat dikatakan bahwa dalam proses pembelajaran peserta didik akan lebih tertarik bila menggunakan media yang bersifat visual, yaitu media yang menyalurkan pesan lewat indera pandang atau penglihatan. Oleh karena itu perlu dibuat multimedia pembelajaran sebagai bentuk inovasi pembelajaran, untuk membuatnya diperlukan sebuah software aplikasi sebagai perangkat pendukung untuk mengatasi masalah di atas. Software yang digunakan untuk memudahkan dalam membuat multimedia pembelajaran adalah CorelDRAW X6 dan Adobe Flash CS6.

Dengan memperhatikan luasnya cakupan materi Elektronika Analog dan Digital maka batasan masalah dalam penelitian ini adalah membahas tentang Rangkaian Logika. Materi ini dipilih karena materi rangkaian logika berkaitan dengan mata kuliah selanjutnya, yaitu Sistem Microprocessor dan Teknik Kendali Digital. Rumusan masalah penelitian ini adalah: 1) Bagaimana desain multimedia pembelajaran pada Mata Kuliah Elektronika Analog dan Digital menggunakan aplikasi CorelDRAW X6 dan Adobe Flash CS6, 2) Bagaimana tanggapan mahasiswa Prodi Pendidikan Teknik Informatika dan Komputer UNM terhadap Multimedia Pembelajaran Elektronika Analog dan Digital menggunakan aplikasi CorelDRAW X6 dan Adobe Flash CS6 ?

\section{METODE PENELITIAN}

\section{A. Metode Peneltian}

Penelitian ini menggunakan metode penelitian dan pengembangan 3Ds dan 1E [3], model ini dimaksudkan untuk menyajikan secara garis besar untuk suatu proyek, tetapi dapat dimodifikasi atau diperluas sesuai dengan kebutuhan. Model ini menyediakan kerangka kerja untuk tahapan proyek multimedia, tetapi tidak meniadakan pendekatan konstruktivis untuk desain individu atau pengembangan.

Model ini terdiri dari 4 tahapan, yaitu Decide, Design, Develop, dan Evaluate [4]. Decide, tahap ini terdiri dari penentuan tujuan proyek, menyusun pedoman proyek, termasuk perencanaan awal dalam mengembangkan suatu produk Design, tahap ini menentukan struktur program dan rincian isi, termasuk mendesain web e-learning yang akan dikembangkan. Develop, tahap ini terdiri dari memproduksi elemen media dan pemograman proyek. Evaluate, tahap ini melihat secara keseluruhan proses yang terjadi dalam pengembangan multimedia.

\section{B. Lokasi dan Subjek Penelitian}

Penelitian ini dilakukan di Jurusan Pendidikan Teknik Elektro Fakultas Teknik Universitas Negeri Makassar dan waktu pelaksanaan penelitian dilakukan mulai Desember 2016 sampai Maret 2017. Subjek penelitian adalah mahasiswa Program Studi di 
Pendidikan Teknik Informatika dan Komputer UNM yang memprogramkan mata kuliah Elektronika Analog dan Digital sebanyak 34 orang mahaqsiswa.

\section{HASIL PENELITIAN}

\section{A. Hasil Penelitian}

Tampilan akhir dari setiap halaman. merupakan hasil printscreen dari Adobe Flash Cs6 ke MS. Word sehingga animasi tidak terlihat lagi. Tampilan dengan animasi dapat dilihat langsung pada saat program dijalankan.

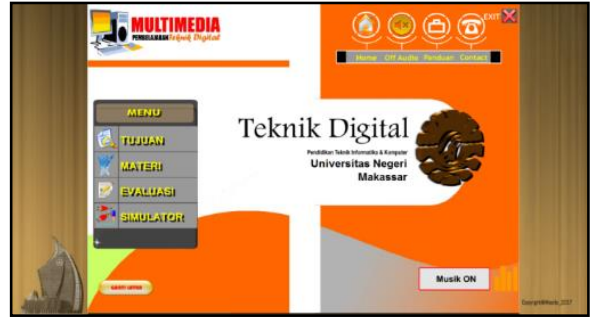

Gambar 1. Tampilan Home

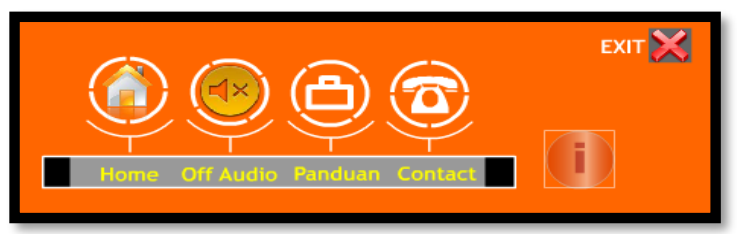

Gambar 2. Tampilan Menu Home, OffAudio Panduan Contact dan Exitdan (b)Menu Tujuan, Materi, Evaluasi dan Simulator

Gambar 2 merupakan bagian dari media pembelajaran elektronika analog dan digital yang berisi tampilan awal (home) yang terdiri dari menu home, audio ,off audio, panduan, contact, tujuan, materi, eveluasi, simulator, ganti lantar, volume audio dan menu exit.

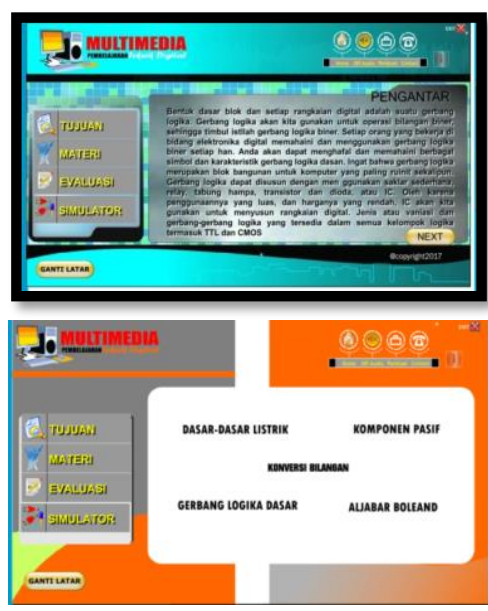

Gambar 3. Tampilan Materi Tampilan Pilihan Materi

\section{B. Analisis Data}

1. Uji Kelayakan

Hasil dari uji kelayakan/validasi oleh dosen ahli sebagai validator disajikan pada Tabel 1.

TABEL 1. HASIL PENILAIAN VALIDATOR

\begin{tabular}{|c|c|c|c|}
\hline Penilain & Skor Maksimum & Skor & Kelayakan \\
\hline Validator I & 65 & 62 & $95 \%$ \\
\hline Validator II & 65 & 60 & $92 \%$ \\
\hline \multicolumn{2}{|r|}{ Total } & 122 & $94 \%$ \\
\hline
\end{tabular}

Berdasarkan Tabel 1, diperoleh data bahwa validasi ahli media terhadap media pembelajaran elektronika analog dan digital mendapat skor 62 dari skor maksimum 65 , dengan persentase $95 \%$, berada pada kategori layak dan validator dua member skor 60 dari skor maksimum 65, dengan persentase $92 \%$. Rata-rata hasil validasi antara validator satu dan validator dua diperoleh nilai $94 \%$ nilai kelayakan.

Validasi yang telah dilakukan oleh ahli yaitu Validator I memberikan skor nilai 62 dengan persentase $95 \%$ dimana nilai maksimal yaitu 65 dan Validator II memberikan skor 62 dengan persentase 92\% berdasarkan hasil penilain ahli maka dapat disimpulkan bahwa multimedia pembelajaran layak digunakan untuk uji coba lapangan.

\section{Uji Coba Kelompok Kecil}

Pengambilan data tanggapan mahasiswa terhadap media pembelajaran dilakukan dengan menggunakan metode penyebaran dan pengisian angket. Data hasil uji coba kelompok besar dianalisis menggunakan Statistical Product and Sevice Solution (SPSS) 23.0 dan Microsoft Excel 2007 dengan bantuan komputer. Kemudian hasil analisis disajikan pada Tabel 2 berikut ini :

\begin{tabular}{lr} 
TABEL 2.STATISTIK DESKRIPTIF UJI KELOMPOK KECIL \\
\cline { 2 - 2 } Mean & 153,14 \\
Std. Error of Mean & 6,519 \\
Median & 160,00 \\
Mode & $121^{\mathrm{a}}$ \\
Std. Deviation & 17,247 \\
Variance & 297,476 \\
Minimum & 121 \\
Maximum & 172 \\
\hline
\end{tabular}

Berdasarkan data hasil statistik deskriptif pada Tabel 3, diperoleh data minimum $=121$; maksimum $=172$, Median $=160.00 ;$ dan standar deviasi $=17,247$. Setelah data tersebut diketahui, data tersebut disajikan ke dalam tabel distribusi frekuensi tanggapan mahasiswa terhadap Media Pembelajaran Elektronika Analog dan Digital. Tanggapan mahasiswa tersebut dikategorikan dalam 5 kategori 
yaitu sangat baik, baik, cukup baik, kurang, sangat kurang.

TABEL 3. DISTRIBUSI FREKUENSI UJI COBA KELOMPOK KECIL

\begin{tabular}{|c|c|c|c|c|c|c|}
\hline \multirow{3}{*}{$\begin{array}{l}\text { KATEGORI } \\
\text { Sangat Baik }\end{array}$} & \multirow{2}{*}{\multicolumn{3}{|c|}{ INTERVAL }} & \multirow{3}{*}{$\begin{array}{c}\text { FA } \\
5\end{array}$} & \multicolumn{2}{|c|}{ Persentase\% } \\
\hline & & & & & \multirow{2}{*}{$\begin{array}{c}\mathbf{F r} \\
71,4 \%\end{array}$} & \multirow{2}{*}{\begin{tabular}{|c|}
$\mathbf{F k}$ \\
$71,4 \%$
\end{tabular}} \\
\hline & 146,8 & - & 175 & & & \\
\hline Baik & 117,8 & - & 145,8 & 2 & $28,6 \%$ & $100 \%$ \\
\hline Cukup Baik & 88,6 & - & 116,8 & 0 & $0, \%$ & $0 \%$ \\
\hline Kurang & 59,4 & - & 87,6 & 0 & $0 \%$ & $0 \%$ \\
\hline \multirow[t]{2}{*}{$\begin{array}{l}\text { Sangat } \\
\text { Kurang }\end{array}$} & 30,2 & - & 58,4 & 0 & $0 \%$ & $0 \%$ \\
\hline & & & & 7 & 100 & \\
\hline
\end{tabular}

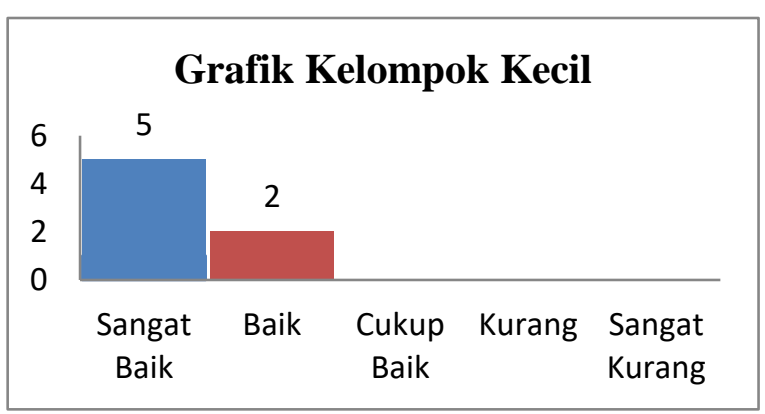

Gambar 4. Histogram Uji Coba Kelompok Kecil

Jika data pada Tabel 3 digambarkan dalam bentuk histogram, maka grafik pandangan mahasiswa terhadap Media Pembelajaran Elektronika Analog dan Digital pada uji coba kelompok kecil dapat dilihat pada Gambar 4.

Berdasarkan Tabel 3 dan Gambar 4, tanggapan mahasiswa terhadap Media Pembelajaran Elektronika Analog dan Digital pada kategori sangat baik dengan jumlah mahasiswa sebanyak 5 orang dengan nilai persentase $(71,4 \%)$; kategori baik dengan jumlah mahasiswa sebanyak 2 orang $(28,6 \%)$; sementara itu tidak ada pada kategori cukup baik, kurang dan sangat kurang. Berdasarkan jumlah persentase pada kategori sangat baik $(71,4 \%)$ dan pada kategori baik $(28,6 \%)$ sementara pada kategori cukup baik, kurang, dan sangat kurang pada kategori $0,0 \%$ maka dapat disimpulkan bahwa media pembelajaran sangat layak untuk digunakan dalam uji coba kelompok besar.

\section{Uji Coba Kelompok Besar}

Aspek penilaian uji coba kelompok besar yaitu aspek: (1) pembelajaran; (2) isi; (3); tampilan; (4) pengunaan.
TABEL 4. DISRIBUSI FREKUENSI UJI COBA KELOMPOK BESAR

\begin{tabular}{|c|c|c|c|c|c|c|}
\hline \multirow{3}{*}{$\begin{array}{l}\text { KATEGORI } \\
\text { Sangat Baik }\end{array}$} & \multirow{2}{*}{\multicolumn{3}{|c|}{ INTERVAL }} & \multirow{3}{*}{$\begin{array}{r}\text { FA } \\
31\end{array}$} & \multicolumn{2}{|c|}{ Persentase \% } \\
\hline & & & & & \multirow{2}{*}{$\begin{array}{c}\mathbf{F r} \\
91,2\end{array}$} & \multirow{2}{*}{$\begin{array}{c}\mathbf{F k} \\
50.0\end{array}$} \\
\hline & 138 & - & 165 & & & \\
\hline Baik & 111 & - & 137 & 2 & 5,9 & 97,1 \\
\hline Cukup Baik & 83 & - & 110 & 1 & 2,9 & 100,0 \\
\hline Kurang & 56 & - & 82 & 0 & 0,0 & 100,0 \\
\hline \multirow[t]{2}{*}{ Sangat Kurang } & 28 & - & 55 & & & \\
\hline & & & & 34 & 100 & \\
\hline
\end{tabular}

Disribusi frekuensi pada Tabel 4 di atas menunjukkan pengkategorian tanggapan mahasiswa terhadap pengunaan media pembejalaran berbasis multimedia pada mata kuliah elektronika analog dan digital. Berdasarkan nilai pada tabel tersebut menunjukan pada kategori sangat baik berada pada interval 138-165 dengan jumlah $\mathrm{FA}=31, \mathrm{Fr}=91,2 \%$ dan $\mathrm{Fk}=91,2 \%$ kategori baik berada pada interval 111-137 dengan jumlah $\mathrm{FA}=2, \quad \mathrm{Fk}=5,9 \%$ dan $\mathrm{Fk}=97,1 \%$, kategori cukup baik berada pada interval 83-110 dengan jumlah $F A=1$ dan $0,0 \%$ atau $\mathrm{Fk}=97,1 \%$ sementara interval cukup baik berada pada interval 83-110 dengan nilai $\mathrm{FA}=1, \mathrm{Fr}=2,9 \%$ atau $\mathrm{Fk}=100 \%$ dan interval sangat kurang berada pada nilai 28-55 dan $\mathrm{FA}=0$ atau $\mathrm{Fk}=100 \%$ jika data tersebut disajikan dalam dalam betuk histogram, maka data tanggapan mahasiswa terhadap media pembelajaran berbasis multimedia sebagai berikut:

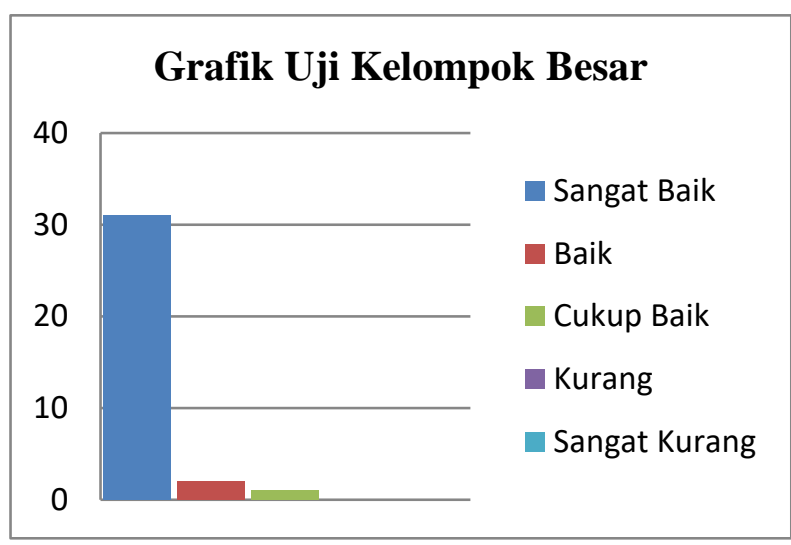

Gambar 5. Histogram Hasil Uji Kelompok Besar

Berdasarkan Tabel 4 dan Gambar 5 diketahui bahwa dari 34 mahasiswa, 31 orang atau $91,2 \%$ menyatakan sangat baik, 2 orang atau 5,9\% menyatakan baik, dan 1 orang atau 2,9\% cukup baik. Berdasarkan hasil stastistik tersebut, menunjukan bahwa mahasiswa memiliki pandangan yang sangat positif terhadap pengunaan media pembelajaran berbasis multimedia. 


\section{SIMPULAN}

Berdasarkan hasil penelitian yang diuraikan pada bab sebelumnya, maka dapat diambil kesimpulan bahwa:

1. Pengembangan Multimedia pembelajaran Elektronika Analog dan Digital dikembangkan dengan menggunakan CorelDrawX6 dan Adobe Flash CS6 dengan menggunakan model pengembangan 4D yaitu, define (pendefinisian), design (perancangan), development (pengembangan), dan disseminate (penyebaran) yang dapat diintegrasikan dengan media gambar audio dan animasi.

2. Tanggapan mahasiswa Prodi PTIK UNM Angkatan 2016 terhadap penggunaan media pembelajaran Mata Kuliah Elektronika Analog dan Digital berada dalam kategori sangat baik.

\section{DAFTAR PUSTAKA}

[1] H. Bakri, "Desain media pembelajaran animasi berbasis adobe flash CS3 pada mata kuliah instalasi listrik 2," Jurnal Medtek, vol. 3, no. 2, pp. 3-4, 2011.

[2] N. Saharuddin, "Pengembangan Media Pembelajaran Berbasis $\mathrm{Ar}$ (Augmentedreality) Pada Mata Kuliah Perangkat Keras Prodi Ptik Universitas Negeri Makassar," Universitas Negeri Makassar, 2016.

[3] K. S. Ivers and A. E. Barron, Multimedia Projects in Education: Designing, Producing and Assessing. Libraries Unlimited. Teacher Ideas Press, Westport, 2002.

[4] I. A. Putri, S. Siswoyo, and W. Indrasari, "Pengembangan media pembelajaran fisika menggunakan lectora inspire pada materi usaha dan energi SMA," Jurnal Penelitian \& Pengembangan Pendidikan Fisika, vol. 2, no. 2, pp. 71-78, 2016. 